\title{
Epilepsy Aspects and EEG Patterns in Neuro-Metabolic Diseases
}

\author{
Ilhem Ben Youssef-Turki, Ichraf Kraoua, Sourour Smirani, Kchaou Mariem, \\ Hanene BenRhouma, Aida Rouissi, Neziha Gouider-Khouja \\ Department of Child and Adolescent Neurology, National Institute of Neurology, Tunis, Tunisia \\ E-mail:ngkhouja@gmail.com,neziha.khouja@rns.tn
}

Received January 18, 2011; revised April 2, 2011; accepted April 4, 2011

\begin{abstract}
Neurometabolic diseases (NMD) are a frequent cause of epilepsy in children. Epilepsy is more frequently part of a complex clinical picture than a predominant symptom and may be of different types and various EEG patterns. The primary goal of this article is, departing from a large personal series, to describe the seizure type, EEG patterns and response to antiepileptic drugs in NMD and to discuss clinical value of epilepsy type in the setting of specific NMD. We found epilepsy was associated to NMD in $43.1 \%$. Disorders of energy metabolism were the most frequent cause of epilepsy (61.3\%). We observed generalized epilepsy in $75 \%$ of the patients with partial epilepsy in $25 \%$. EEG was abnormal in only $71 \%$ of cases with variable patterns. Resistance to antiepileptic drugs was observed in $75 \%$ of cases. Valproate acid was incriminated in seizure worsening in $22.7 \%$ of the patients, all of them affected by mitochondriopathies.
\end{abstract}

Keywords: Neurometabolic Diseases, Epilepsy, EEG

\section{Introduction}

Inborn errors of metabolism (IEM) are a group of genetic disorders characterized by dysfunction of an enzyme or other protein involved in cellular metabolism [1]. Most IEMs involve the nervous system (neuro-metabolic diseases or NMD). NMD often present with a complex clinical picture: psychomotor retardation and/or regression, pyramidal signs, ataxia, hypotonia, movement disorders and epilepsy [1]. Epilepsy is more frequently part of this complex picture than a predominant symptom and presents with various clinical and EEG features. The primary goal of this article is, departing from a large personal series, to describe the seizure types, EEG patterns and response to antiepileptic drugs in NMD.

\section{Patients and Methods}

We included in our prospective study 102 subsequent patients with confirmed or highly suspected NMD followed at the Department of Child and Adolescent Neurology at the National Institute of Neurology of Tunis over 5 years $(2005$ - 2010). We found 44 patients out of these $102(43.1 \%)$ had epilepsy.

In addition, we performed a web search by using the
NIH pubmed database with the following keywords "epilepsy and neurometabolic diseases", "epilepsy and inborn errors of metabolism". We found epilepsy in NMD is mostly reported disease by disease; few studies reported on epilepsy in NMD as a group of disorders [2-11].

\section{Results}

Mean age of our 44 patients ( 25 girls, 19 boys) was 7.8 years (range: 3 months - 20 years). The median age at onset of seizures was 4 years (range: Birth - 16 years), 2 patients had neonatal convulsions. Disorders of energy metabolism (such as mitochondriopathies, pyruvate dehydrogenase (PDH) deficiency and creatine metabolism deficiency) which accounted for $60 \%$ of all our NMD patients, accounted for the almost similar proportion of NMD patients with epilepsy $(61.3 \%, 27 / 44) .25 \%(11 / 44)$ of the patients with NMD and epilepsy had a disorder of complex molecules (such as ceroide lipofuscinosis, metachromatic leukodystrophy, GM2 gangliosidosis, Gaucher disease type III, Niemann Pick type C and Sanfilippo disease), accounting for $25 \%$ of all our NMD patients. Five patients (11.4\%) with NMD and epilepsy had a disorder giving rise to intoxication (phenylketonu- 
ria, biotinidase deficiency and porphyria) accounted for the remaining 5/44 and one patient had Aicardi Goutières syndrome) (Table 1).

The main cause of energy metabolism disorder was mitochondriopathy, which was found in $19(70 \%)$ out of the 27 patients with this group of disorders.

As for patients with complex molecules disorders and epilepsy, this study shows that the most frequent type of epilepsy is progressive myoclonic epilepsy (PME), with GM2 gangliosidosis, Austin leukodystrophy and Sanphilipo disease observed each in 2 patients. Ceroidelipofuscinosis, Gaucher disease type III, Niemann Pick type $\mathrm{C}$ disease, and metachromatic leukodystrophy were observed each in one patient.

The relative frequency of different epilepsy types is shown on Table 2. We observed generalized epilepsy in $33 / 44(75 \%)$ of the patients, with specific epileptic syndromes being rare (only 3 cases of West syndrome). Partial epilepsy was observed in 11/44 (25\%) of the patients.

In $50 \%$ of the cases, epilepsy was the initial symptom of the metabolic disorder. It was in some cases observed in the setting of a metabolic "crisis" or decompensation of the causative disorder (porphyric crisis in porphyria, acute episode of a mitochondrial encephalopathy with lactatic acidosis and stroke like episodes (MELAS), hypoglycaemia in hyperinsulinism and ionic disorder in adrenoleukodystrophy). Status epilepticus (generalized or partial) was observed in 7 patients $(15.9 \%)$ especially in the group of energy metabolism disorders

EEG was abnormal in $71 \%$ of cases with variable EEG patterns: slow background, generalized discharges of spikes-waves, with pseudo-rythmic aspects, fast EEG rhythms, continuous spikes-waves during sleep (CSWS), fragmental hypsarythmia during sleep and photo-paroxysmal responses during photic intermittent stimulation. No suppression bursts were observed.

With regard to antiepileptic drug effect on epilepsy in NMD, resistance was observed in $75 \%$ of cases. Valproate acid was directly incriminated in seizure worsening in 10 cases of mitochondriopathies.

\section{Discussion}

We report on a prospective series of 44 patients with neurometabolic disease (NMD) and epilepsy and we describe the etiologies and the characteristics of epilepsy in these disorders.

Epilepsy in NMD is more frequently part of complex clinical picture than a predominant symptom and presents with various clinical and EEG features. According to our study, nearly half of the patients with NMD may have epilepsy (43\%).

When managing a patient with epilepsy especially inaugural, NMD should be suspected if: (1) the medical history shows consanguinity, family history of similar cases, onset at the neonatal period or psychomotor regression; (2) presence of myoclonus, spasms, focal and

Table 1. Neurometabolic diseases with Epilepsy.

\begin{tabular}{|c|c|c|}
\hline NMD groups & Neurometabolic diseases & Number of patients \\
\hline \multirow{3}{*}{$\begin{array}{l}\text { Energy metabolism } \\
(27 / 44)\end{array}$} & Mitochondriopathies & 19 \\
\hline & Creatine deficiency & 2 \\
\hline & PDH deficiency & 1 \\
\hline \multirow{3}{*}{$\begin{array}{l}\text { Intoxication } \\
(5 / 44)\end{array}$} & Phenylketonuria & 3 \\
\hline & Biotinidase deficiency & 1 \\
\hline & Phorphyria & 1 \\
\hline \multirow{6}{*}{$\begin{array}{l}\text { Molecule complexe } \\
(11 / 44)\end{array}$} & Leukodystrophies & 4 \\
\hline & Ceroide lipofuscinosis & 1 \\
\hline & Niemann pick type $\mathrm{C}$ disease & 1 \\
\hline & Sanphilipo disease & 2 \\
\hline & Gaucher disease type III & 1 \\
\hline & Aicardi goutière syndrome & 1 \\
\hline Total & & 44 \\
\hline
\end{tabular}


Table 2. Frequency and type of epileptic seizures in 44 patients with NMD.

\begin{tabular}{|c|c|c|c|c|c|c|c|c|c|c|c|}
\hline \multirow[b]{2}{*}{$\begin{array}{l}\text { NMD } \\
\text { groups }\end{array}$} & \multirow[b]{2}{*}{$\begin{array}{c}\text { Neurometabolic } \\
\text { disease }\end{array}$} & \multirow[b]{2}{*}{$\begin{array}{l}\text { Number } \\
\text { of patient }\end{array}$} & \multicolumn{6}{|c|}{ Generalized seizures } & \multicolumn{2}{|c|}{ Partial seizures } & \multirow{2}{*}{$\begin{array}{c}\text { Particular } \\
\text { syndrome } \\
\text { West } \\
\text { syndrome }\end{array}$} \\
\hline & & & $\begin{array}{c}\text { Tonico- } \\
\text { clonic }\end{array}$ & Absence & Clonic & Tonic & Atonic & Myoclonus & $\begin{array}{l}\text { Partial } \\
\text { simple }\end{array}$ & $\begin{array}{c}\text { Partial } \\
\text { complexe }\end{array}$ & \\
\hline \multirow{5}{*}{$\begin{array}{l}\text { Energy } \\
\text { metabolism }\end{array}$} & Mitochondriopathies & 19 & ++ & ++ & ++ & ++ & ++ & ++ & + & + & + \\
\hline & PDH deficiency & 1 & + & - & - & + & + & + & - & - & - \\
\hline & Creatine deficiency & 2 & + & - & + & - & - & - & - & - & - \\
\hline & Hyperinsulinism & 1 & ++ & - & - & - & + & - & - & - & - \\
\hline & Lafora disease & 4 & ++ & ++ & ++ & - & - & ++ & ++ & + & - \\
\hline \multirow{3}{*}{ Intoxication } & Phenylketonuria & 3 & ++ & - & + & + & + & - & - & - & + \\
\hline & $\begin{array}{l}\text { Biotinidase } \\
\text { deficiency }\end{array}$ & 1 & ++ & + & - & + & - & + & - & - & - \\
\hline & Porphyria & 1 & ++ & - & - & - & - & - & - & - & - \\
\hline \multirow{4}{*}{$\begin{array}{l}\text { Complexe } \\
\text { molecule }\end{array}$} & Gangliosidosis GM2 & 2 & ++ & - & - & + & - & ++ & - & + & - \\
\hline & $\begin{array}{l}\text { Ceroide } \\
\text { lipofuscinosis }\end{array}$ & 1 & ++ & ++ & + & - & - & ++ & - & - & - \\
\hline & $\begin{array}{l}\text { Niemann pick type } \mathrm{C} \\
\text { disease }\end{array}$ & 1 & - & - & - & + & + & - & + & - & - \\
\hline & $\begin{array}{l}\text { Gaucher disease type } \\
\text { III }\end{array}$ & 1 & - & - & - & - & - & - & - & - & - \\
\hline Others & $\begin{array}{l}\text { Aicardi Goutieres } \\
\text { syndrome }\end{array}$ & 1 & + & - & - & - & - & - & - & + & - \\
\hline
\end{tabular}

and tonic seizures, unexplained status epilepticus or seizures related to eating times; (3) association with a neurological deterioration or systemic signs; (4) presence of early or progressive myoclonic epilepsy; (5) seizures worsen under certain anti-epileptic drugs such as valproate; (6) EEG patterns shows suppression burst, high voltage and rhythmic delta-slow waves associated with myoclonus and paroxysmal responses during photic intermittent stimulation at low frequencies [2-11].

Various NMD causing epilepsy may be suspected according to age at onset and the presence or absence of specific epileptic syndromes (Figure 1). In the neonatal period, early myoclonic encephalopathy (EME) with suppression burst EEG pattern is often due to an inborn error of metabolism, particularly non ketotic hyperglycinemia [12]. If seizures are unexplained and refractory, vitamin-responsive epilepsies should be always considered and therapeutic trial using successively pyridoxine, pyridoxal phosphate, folinic acid and biotin should be started [13-17]. In our series no cases of early myoclonic encephalopathy were found probably because epileptic patients in the neonatal period are referred to neonatologists rather than neurologists.

In early infancy, many treatable conditions should be considered: serine deficiency, GLUT1 deficiency, biotinidase deficiency, aminoacidopathies and urea cycle defects [16-19]. Other less readily treatable diseases (mitochondriopathies, sulfite oxidase deficiency, adenylo- succinate lyase deficiency, succinic semialdehyde dehydrogenase, peroxysomal disorders and CDG syndromes) could be also searched for [20-25]. In our study, mitochondriopathies were the most frequent disease, accounting for $70 \%$ of cases. We found one case with a possibly treatable NMD (biotinidase deficiency).

In childhood (as it is the case in adulthood), diagnosis approach is based on the presence or absence of progressive myoclonic epilepsy (PME). The causes of PME are dominated by lysosomal disorders, like in our study, (ceroide-lipofuscinosis, sialidosis, GM2 gangliosidosis, Gaucher disease type III, Niemann Pick type C), Lafora disease and mitochondriopathies [26-32]. In the absence of PME, treatable diseases (such as GLUT1 deficiency, creatine deficiency, porphyria and urea cycle disorders) should be considered [33-35]. Finally, other non treatable diseases (mainly mitochondriopathies) should be evoked. In our study, PME was the most prevalent epileptic syndrome in childhood.

Epilepsy may be symptomatic of a metabolic" crisis" or decompensation, as it was the case in 4 out 44 of our patients, and these cases were diagnosed as, porphyria, mitochondrial encephalopathy with lactic acidosis and stroke like episodes (MELAS), hyperinsulinism and adrenoleukodystrophy [2].

EEG findings in epilepsy related to NMD are non specific; however some EEG patterns are suggestive of some NMD groups: suppression burst is highly sugges- 


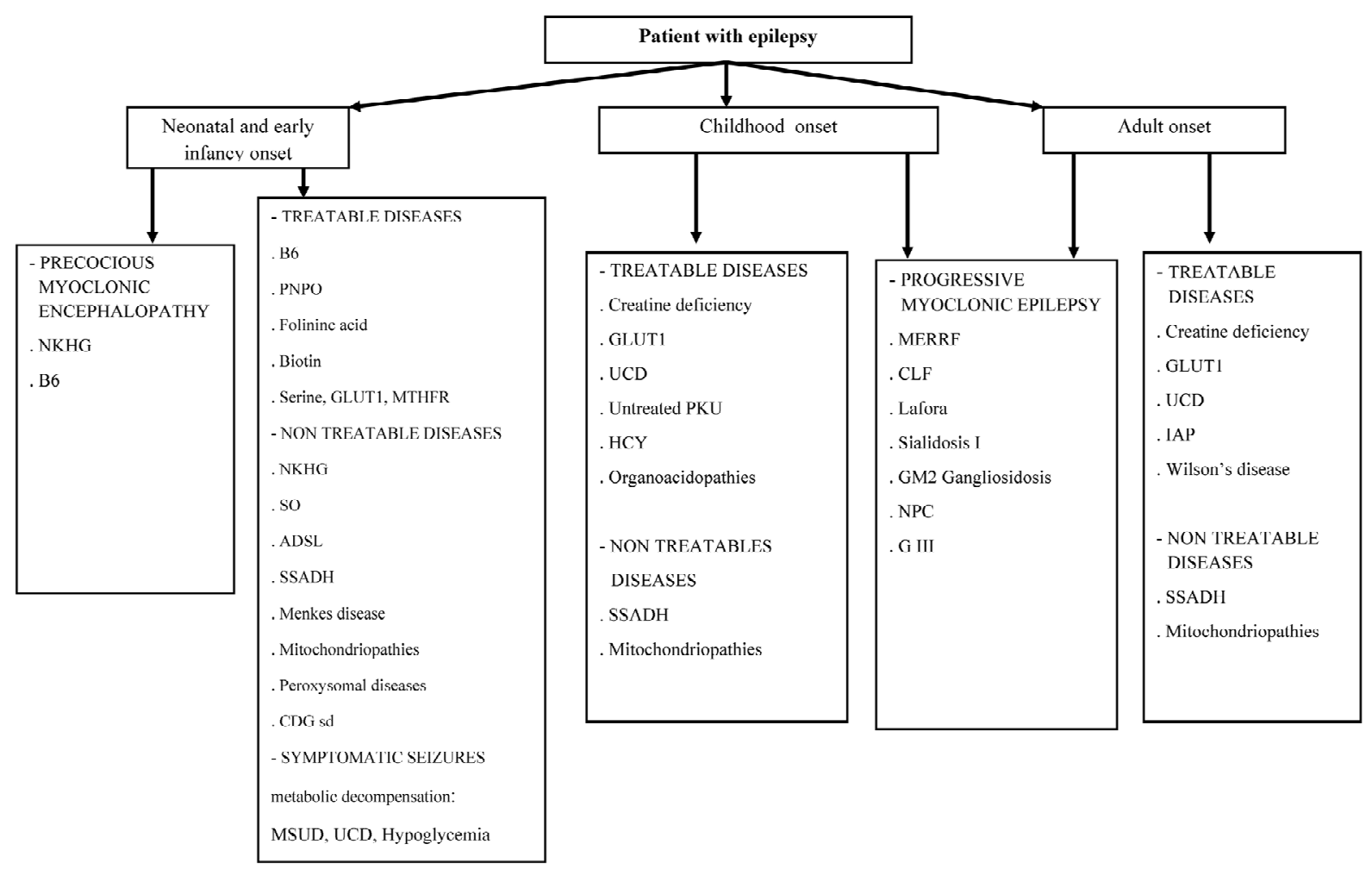

Figure 1. Diagnosis orientation in NMD according to the age at onset and epileptic syndromes. Abreviation: NKHG: Non ketotic hyperglycinemia; B6: pyridoxine-dependent epilepsy; PNPO: pyridoxal phosphate deficiency; GLUT1: glucose transporter deficiency; MTHFR: methyltetrahydrofolate deficiency; SO: sulfite oxidase deficiency; ADSL: adenylosuccinate lyase deficiency; SSADH: succinic semialdhehyde dehydrogenase; CDG SD: carbohydrate deficiency syndrome; MSUD: maple syrup urine disease; UCD: urea cycle disorders; PKU: phenylketonuria; HCY: homocystinuria; MERRF: myoclonic epilepsy with ragged red fibers; CLF: ceroid lipofuscinosis; NPC: Niemann Pick disease; G III: Gaucher disease type III; IAP: intermittent acute porphyria.

tive of non ketotic hyperglycinemia and high voltage and rhythmic delta-slow waves associated with myoclonus and paroxysmal responses during photic intermittent stimulation is highly suggestive of PME [11]. In our study we observed no suppression bursts.

Epilepsy in NMD is usually pharmacoresistant. Antiepileptic drugs (AEDs) provide a moderate benefit as compared to more specific metabolism-directed therapies (eg special diet or vitamins). Some AEDs, (such as valproate) may worsen the clinical condition as they interfere with the abnormal metabolic pathway, especially in mitochondriopathies, urea cycle deficiency and non ketotic hyperglycinemia [7]. In our series valproate was incriminated in seizure worsening in 10 patients with mitochondriopathy.

\section{Conclusions}

Nearly half or the patients with NMD would present an epilepsy of various types (the most life-threatening being status epilepticus) that may be inaugural (50\% of cases) of the disease or symptomatic of a metabolic decompen- sation. The most frequent provider of epilepsy is the group of energy metabolism, most probably because it is the most frequent group of NMD but may be also because it is a group of disorders in which the neuronal metabolism is more fragile and susceptible of suffering from any situation of fever or hypercatabolism. Diagnosis approach to a patient with epilepsy and a suspected underlying NMD depends on age, presence or absence of a specific epileptic syndrome and/or a specific EEG pattern. A thorough diagnosis evaluation of patients with epilepsy and NMD allows efficient management of the underlying NMD but also of epilepsy itself, in case the NMD is a treatable one. It also allows (with the adequate measures) avoiding harmful AEDs, preventing metabolic "crisis" and epilepsy worsening.

\section{References}

[1] J. M. Saudubray, F. Sedel and J. H. Walter, "Clinical Approach to Treatable Inborn Metabolic Diseases: An Introduction," Journal of Inherited Metabolic Disease, Vol. 29, No. 2-3, 2006, pp. 261-274. 


\section{doi:10.1007/s10545-006-0358-0}

[2] N. Bahi-Buisson, K. Mention, P. L. Léger, et al., "Neonatal Epilepsy and Inborn Errors of Metabolism," Archives de Pédiatrie, Vol. 13, No. 3, 2006, pp. 284-292.

[3] D. C. De Vivo, "Inherited Metabolic Disorders and Seizures in Infancy," Journal of Child Neurology, Vol. 17, 2002, pp. 3S1-3S2.

[4] D. R. Jr. Nordli and D. C. De Vivo, "Classification of Infantile Seizures: Implications for Identification and Treatment of Inborn Errors of Metabolism," Journal of Child Neurology, Vol. 17, 2002, pp. 3S3-3S7.

[5] J. M. Pascual, J. Campistol and A. Gil-Nagel, "Epilepsy in Inherited Metabolic Disorders," Neurologist, Vol. 14, 2008, pp. S2-S14.

[6] P. L. Pearl, H. D. Bennett and Z. Khademian, "Seizures and Metabolic Disease," Current Neurology and Neuroscience Reports, Vol. 5, No. 2, 2005, pp. 127-133.

[7] F. Sedel, I. Gourfinkel-An, O. Lyon-Caen, M. Baulac, J. M. Saudubray and V. Navarro, "Epilepsy and Inborn Errors of Metabolism in Adults: A Diagnostic Approach," Journal of Inherited Metabolic Disease, Vol. 30, No. 6, 2007, pp. 846-854. doi:10.1007/s10545-007-0723-7

[8] S. Stöckler-Ipsiroglu and B. Plecko, "Metabolic Epilepsies: Approaches to a Diagnostic Challenge," Canadian Journal of Neurological Sciences, Vol. 36, 2009, pp. S67-S72.

[9] F. Vigevano and A. Bartuli, "Infantile Epileptic Syndromes and Metabolic Etiologies," Journal of Child Neurology, Vol. 17, 2002, pp. S9-S13.

[10] N. I. Wolf, T. Bast and R. Surtees, "Epilepsy in Inborn Errors of Metabolism," Epileptic Disorders, Vol. 7, No. 2, 2005, pp. 67-81.

[11] N. I. Wolf, A. García-Cazorla and G. F. Hoffmann, "Epilepsy and Inborn Errors of Metabolism in Children," Journal of Inherited Metabolic Disease, Vol. 32, No. 5, 2009, pp. 609-617.

[12] D. A. Applegarth and J. R Toone, "Glycine EncephaLopathy (Nonketotic Hyperglycinaemia): Review and Update," Journal of Inherited Metabolic Disease, Vol. 27, No. 3, 2004, pp. 417-422.

[13] P. Baxter, P. Griffiths, T. Kelly, et al., "Pyridoxine-dependent Seizures: Demographic, Clinical, MRI and Psychometric Features, and Effect of Dose on Intelligence Quotient," Developmental Medicine \& Child Neurology, Vol. 38, No. 11, 1996, pp. 998-1006.

[14] M. F. Kuo and H. S. Wang, "Pyridoxal Phosphate-responsive Epilepsy with Resistance to Pyridoxine," Pediatric Neurology, Vol. 26, No. 2, 2002, pp. 146-147. doi:10.1016/S0887-8994(01)00357-5

[15] O. A. Torres, V. S. Miller, N. M. Buist, et al., "Folinic Acid-responsive Neonatal Seizures," Journal of Child Neurology, Vol. 14, 1999, pp. 529-532. doi:10.1177/088307389901400809

[16] J. E. Collins, N. S. Nicholson, N. Dalton, et al., "Biotinidase Deficiency: Early Neurological Presentation," Developmental Medicine \& Child Neurology, Vol. 36, 1994, pp. 268-270.
[17] B. A. Salbert, J. M. Pellock and B. Wolf, "Characterization of Seizures Associated with Biotinidase Deficiency," Neurology, Vol. 43, No. 7, 1993, pp.1351-1355.

[18] T. J. De Koning and L. W. Klomp, "Serine-deficiency Syndromes," Current Opinion in Neurology, Vol. 17, No. 2, 2004, pp. 197-204. doi:10.1097/00019052-200404000-00019

[19] K. Brockmann, D. Wang, C. G. Korenke, et al., "Autosomal Dominant Glut-1 Deficiency Syndrome and Familial Epilepsy," Annals of Neurology, Vol. 50, 2001, pp. 476-485. doi:10.1002/ana.1222

[20] J. Finsterer, "Central Nervous System Manifestations of Mitochondrial Disorders," Acta Neurologica Scandinavica, Vol. 114, 2006, pp. 217-238.

[21] A. B. Dublin, J. K. Hald and S. L. Wootton-Gorges, "Isolated Sulfite Oxidase Deficiency: MR Imaging Features," American Journal of Neuroradiology, Vol. 23, No. 3, 2002, pp. 484-485.

[22] G. Van den Berghe, M. F. Vincent and J. Jaeken, "Inborn Errors of the Purine Nucleotide Cycle: Adenylosuccinase Deficiency," Journal of Inherited Metabolic Disease, Vol. 20, No. 2, 1997, pp.193-202. doi:10.1023/A:1005304722259

[23] P. L. Pearl, K. M. Gibson, M. T. Acosta, et al., "Clinical Spectrum of Succinic Semialdehyde Dehydrogenase Deficiency," Neurology, Vol. 60, No. 9, 2003, pp.1413-1417.

[24] Y. Takahashi, Y. Suzuki, K. Kumazaki, et al., "Epilepsy in Peroxisomal Diseases," Epilepsia, Vol. 38, No. 2, 1997, pp. 182-188. doi:10.1111/j.1528-1157.1997.tb01095.x

[25] T. Marquardt and J. Denecke, "Congenital Disorders of Glycosylation: Review of Their Molecular Bases, Clinical Presentations and Specific Therapies," European Journal of Pediatrics, Vol. 162, No. 6, 2003, pp. 359-379.

[26] A. Shahwan, M. Farrell and N. Delanty, "Progressive Myoclonic Epilepsies: A Review of Genetic and Therapeutic Aspects," The Lancet Neurology, Vol. 4, No. 4, 2005, pp. 239-248. doi:10.1016/S1474-4422(05)70043-0

[27] K. E. Wisniewski, N. Zhong and M. Philippart, "Pheno/genotypic Correlations of Neuronal Ceroid Lipofuscinoses," Neurology, Vol. 57, No. 4, 2001, pp. 576-581.

[28] J. A. Lowden and J. S. O'Brien, "Sialidosis: A Review of Human Neuraminidase Deficiency," American Journal of Human Genetics, Vol. 31, No. 1, 1979, pp. 1-18.

[29] A. Federico, S. Battistini, S. G. Ciacci, et al., "Cherry-red Spot Myoclonus Syndrome (Type I Sialidosis)," Developmental Neuroscience, Vol. 13, 1991, pp. 320-326.

[30] J. K. Park, E. Orvisky, N. Tayebi, et al., "Myoclonic Epilepsy in Gaucher Disease: Genotype-phenotype Insights from a Rare Patient Subgroup," Pediatric Research, Vol. 53, No. 3, 2003, pp. 387-395.

[31] M. Sevin, G. Lesca, N. Baumann, et al., "The Adult form of Niemann-Pick Disease Type C," Brain, Vol. 130, No. 1, 2007, pp.120-133. doi:10.1093/brain/awl260

[32] S. Ganesh, R. Puri, S. Singh, S. Mittal and D. Dubey, "Recent Advances in the Molecular Basis of Lafora's Progressive Myoclonus Epilepsy," Journal of Human Genetics, Vol. 51, No. 1, 2006, pp. 1-8.

[33] V. Leuzzi, "Inborn Errors of Creatine Metabolism and 
Epilepsy: Clinical Features, Diagnosis, and Treatment," Journal of Child Neurology, Vol. 17, 2002, pp. S89-S97.

[34] A. S. Winkler, T. J. Peters and R. D. Elwes, "Neuropsychiatric Porphyria in Patients with Refractory Epilepsy: Report of Three Cases," Journal of Neurology, Neuro- surgery \& Psychiatry, Vol. 76, No. 3, 2005, pp. 380-383.

[35] G. M. Enns, "Neurologic Damage and Neurocognitive Dysfunction in Urea Cycle Disorders," Seminars in Pediatric Neurology, Vol. 15, No. 3, 2008, pp. 132-139. doi:10.1016/j.spen.2008.05.007 